ACCEPTED MANUSCRIPT • OPEN ACCESS

\title{
Atomic layer deposited nanolaminates of zirconium oxide and manganese oxide from manganese(III)acetylacetonate and ozone
}

To cite this article before publication: Kristjan Kalam et al 2021 Nanotechnology in press https://doi.org/10.1088/1361-6528/abfee9

\section{Manuscript version: Accepted Manuscript}

Accepted Manuscript is "the version of the article accepted for publication including all changes made as a result of the peer review process, and which may also include the addition to the article by IOP Publishing of a header, an article ID, a cover sheet and/or an 'Accepted Manuscript' watermark, but excluding any other editing, typesetting or other changes made by IOP Publishing and/or its licensors"

This Accepted Manuscript is @ 2021 The Author(s). Published by IOP Publishing Ltd..

As the Version of Record of this article is going to be / has been published on a gold open access basis under a CC BY 3.0 licence, this Accepted Manuscript is available for reuse under a CC BY 3.0 licence immediately.

Everyone is permitted to use all or part of the original content in this article, provided that they adhere to all the terms of the licence https://creativecommons.org/licences/by/3.0

Although reasonable endeavours have been taken to obtain all necessary permissions from third parties to include their copyrighted content within this article, their full citation and copyright line may not be present in this Accepted Manuscript version. Before using any content from this article, please refer to the Version of Record on IOPscience once published for full citation and copyright details, as permissions may be required. All third party content is fully copyright protected and is not published on a gold open access basis under a CC BY licence, unless that is specifically stated in the figure caption in the Version of Record.

View the article online for updates and enhancements. 


\title{
Atomic layer deposited nanolaminates of zirconium oxide and manganese oxide from manganese(III)acetylacetonate and ozone.
}

Kristjan Kalam*11, Raul Rammula ${ }^{1}$, Peeter Ritslaid ${ }^{1}$, Tanel Käämbre ${ }^{1}$, Joosep Link ${ }^{2}$, Raivo Stern $^{2}$, Guillermo Vinuesa ${ }^{3}$, Salvador Dueñas ${ }^{3}$, Helena Castán ${ }^{3}$, Aile Tamm ${ }^{1}$, Kaupo Kukli ${ }^{1}$. ${ }^{1}$ Institute of Physics, University of Tartu, W. Ostwald 1, 50411 Tartu, Estonia.

${ }^{2}$ National Institute of Chemical Physics and Biophysics, Akadeemia tee 23, 12618 Tallinn, Estonia.

${ }^{3}$ Department of Electronics, University of Valladolid, Paseo Belén 15, 47011 Valladolid, Spain.

* Corresponding author, e-mail: kristjan.kalam@ut.ee

\begin{abstract}
Atomic layer deposition method was used to grow thin films consisting of $\mathrm{ZrO}_{2}$ and $\mathrm{MnO}_{\mathrm{x}}$ layers. Magnetic and electric properties were studied of films deposited at $300{ }^{\circ} \mathrm{C}$. Some deposition characteristics of the manganese(III)acetylacetonate and ozone process were investigated, such as the dependence of growth rate on the deposition temperature and film crystallinity. All films were partly crystalline in their as-deposited state. Zirconium oxide contained cubic and tetragonal phases of $\mathrm{ZrO}_{2}$, while the manganese oxide was shown to consist of cubic $\mathrm{Mn}_{2} \mathrm{O}_{3}$ and tetragonal $\mathrm{Mn}_{3} \mathrm{O}_{4}$ phases. All the films exhibited nonlinear saturative magnetization with hysteresis, as well as resistive switching characteristics.
\end{abstract}

Keywords: Atomic layer deposition, thin films, magnetic materials, resistive switching

\section{Introduction}

Zirconium and manganese oxide thin films have many applications, for example $\mathrm{ZrO}_{2}$ can be used as an optical coating [1, 2], waveguide [3, 4], gas sensor [5, 6], gate dielectric in a transistor [7], functional layer/of a resistive switching memory [8] and a ferroelectric memory $[9,10]$.

Mn-doped zirconia has also been reported to be a magnetic material [11-12]. Magnetic polarization has been achieved and studied also in Fe, Co and Ni doped zirconia [13], Ca and $\mathrm{Mg}$ doped [14], Ag doped [15] and even in un-doped zirconia [16-17]. $\mathrm{MnO}_{2}$ has been used as 
a catalyst [18] and an electrode [19]. $\mathrm{MnO}$ has been used as electrode material [20]. $\mathrm{Mn}_{2} \mathrm{O}_{3}$ has been used for water splitting devices [21].

Oxides of zirconium and magnesium have been prepared via reactive sputtering [22-23], pulsed laser deposition [1, 14, 24], electron beam evaporation [25-26], chemical vapour deposition [27-28] and spray pyrolysis [29-30].

Zirconium oxide films generally form, in atomic layer deposition (ALD) processes, possessing dioxide $\left(\mathrm{ZrO}_{2}\right)$ stoichiometry and exhibiting crystal structure characteristic of $\mathrm{ZrO}_{2}$ polymorphs, regardless of the precursor chemistry used. For instance, $\mathrm{ZrO}_{2}$ films have been grown by ALD using, e.g., $(\mathrm{CpMe})_{2} \mathrm{ZrMe}_{2}$ or $(\mathrm{CpMe})_{2} \mathrm{Zr}(\mathrm{OMe}) \mathrm{Me}\left(\mathrm{Cp}=\mathrm{C}_{5} \mathrm{H}_{5}, \mathrm{Me}=\mathrm{CH}_{3}\right)$ as $\mathrm{Zr}$ precursors, and $\mathrm{O}_{3}$ as the oxidant at 300 or $350{ }^{\circ} \mathrm{C}$ [31]. Growth of $\mathrm{ZrO}_{2}$ films from $\mathrm{CpZr}\left(\mathrm{NMe}_{2}\right)_{3}$ and $\mathrm{H}_{2} \mathrm{O}$ was investigated in real time at substrate temperatures ranging from 120 to $350{ }^{\circ} \mathrm{C}$ [32]. $\mathrm{ZrO}_{2}$ growth has also been carried out using $\mathrm{ZrCl}_{4}$ and $\mathrm{H}_{2} \mathrm{O}$ as precursors [33] and a similar process has also been monitored in real time [34]. Furthermore, zirconia has been deposited from $\mathrm{Zr}\left[\mathrm{N}\left(\mathrm{C}_{2} \mathrm{H}_{5}\right)\left(\mathrm{CH}_{3}\right)\right]_{4}$ and $\mathrm{H}_{2} \mathrm{O}[9,35]$.

At the same time, in the case of manganese oxide, the stoichiometry can vary, concurrently with the lattice, due to three different valences of manganese. Thus, $\mathrm{MnO}_{2}$ has been atomic layer deposited from $\mathrm{Mn}(\mathrm{thd})_{3}$ (thd = 2,2,6,6-tetramethyl-3,5 heptanedione) and $\mathrm{O}_{3}[21,36]$, $\mathrm{MnO}$ has also been atomic layer deposited using $\mathrm{Mn}(\mathrm{EtCp})_{2}$, and $\mathrm{H}_{2} \mathrm{O}$ [20], $\mathrm{Mn}(\mathrm{thd})_{3}$ and $\mathrm{NH}_{3}$ plasma [21], manganese(III)acetylacetonate, further denoted as $\mathrm{Mn}(\operatorname{acac})_{3}$, and $\mathrm{H}_{2} \mathrm{O}$ [37]. $\mathrm{Mn}_{2} \mathrm{O}_{3}$ has been obtained in the films, after annealing the as-deposited $\mathrm{MnO}_{2}$ or $\mathrm{MnO}$ [21].

This study is devoted to ALD of laminated thin films consisting of $\mathrm{ZrO}_{2}$ and manganese oxide. The purpose was to firstly investigate the process of depositing manganese oxide from $\left(\mathrm{Mn}(\mathrm{acac})_{3}\right)$ and ozone, $\mathrm{O}_{3}$, and, thereafter, study the memory effects in nanolaminated zirconia and manganese oxide. Specifically, possible ferromagnetic, ferroelectric and resistive switching properties of such thin films were probed.

\section{Experimental details}

The films studied in this work were grown in a low-pressure flow-type ALD reactor [38]. $\mathrm{Mn}(\mathrm{acac})_{3}(97 \%$, ACROS Organics) was used as the manganese precursor and evaporated at 
$183{ }^{\circ} \mathrm{C}$. Zirconium precursor, $\mathrm{ZrCl}_{4}\left(99.9 \%\right.$, Aldrich), was evaporated at $157{ }^{\circ} \mathrm{C}$. Both metal precursors were evaporated from a glass boat inside the reactor at a pressure of $220 \mathrm{~Pa}$. Nitrogen, $\mathrm{N}_{2}$ (99.999\%, Eesti AGA AS), was applied as the carrier and purging gas. Ozone was produced from $\mathrm{O}_{2}(99.999 \%$, AGA) using BMT Messtechnik $802 \mathrm{~N}$ generator. The ozone concentration at the reactor inlet, was $245-250 \mathrm{~g} / \mathrm{m}^{3}$ in the experiments. The estimated ozone flow rate from the generator was about $68 \mathrm{scc} / \mathrm{m}$, while the carrier gas flow rate was kept at about $220 \mathrm{scc} / \mathrm{m}$.

One ALD cycle of a binary oxide consists of four sequential pulses. For producing a layer of $\mathrm{ZrO}_{2}$, the sequence was $\mathrm{ZrCl}_{4}$ pulse $-\mathrm{N}_{2}$ purge $-\mathrm{O}_{3}$ pulse $-\mathrm{N}_{2}$ purge. In the case of depositing a manganese oxide layer, the metal precursor was $\mathrm{Mn}(\mathrm{acac})_{3}$, while purging with $\mathrm{N}_{2}$ and oxidizing with $\mathrm{O}_{3}$ was similar to the $\mathrm{ZrO}_{2}$ scheme. Pulse times for depositing both metals were 5-2-2-5 s for the sequence given above. Various layered structures were deposited, for example, 100 cycles of manganese oxide followed by a 100 cycles of zirconia, more details are given in Table I.

$\mathrm{ZrO}_{2}-\mathrm{MnO}_{\mathrm{x}}$ films were grown on cleansed and etched $\mathrm{Si}(100)$ [39] substrate surfaces as well as on surfaces of conductive TiN layers. The TiN bottom electrode layers were pre-deposited on $\mathrm{Si}(100)$ wafers with a resistivity of $0.014-0.020 \Omega \cdot \mathrm{cm}$, i.e., on $\mathrm{Si}$ boron-doped to the concentrations up to $5 \times 10^{18}-1 \times 10^{19} / \mathrm{cm}^{3}$. TiN was grown by pulsed chemical vapour deposition using a batch $\mathrm{TiCl}_{4} / \mathrm{NH}_{3}$ process [40-41] at temperatures of $450-500{ }^{\circ} \mathrm{C}$ in an ASM A412 Large Batch $300 \mathrm{~mm}$ reactor at Fraunhofer IPMS-CNT. The films, which were deposited on TiN substrates for electrical measurements, were also supplied with $\mathrm{Ti}$ electrodes (area $0.204 \mathrm{~mm}^{2}$ ) electron-beam evaporated on top of the films. The structure to conduct electrical measurements was, from top to bottom, $\mathrm{Ti} / \mathrm{ZrO}_{2}-\mathrm{MnO}_{\mathrm{x}} / \mathrm{TiN} / \mathrm{Si} / \mathrm{Al}$.

Spectroscopic ellipsometer (SE), model GES5-E, was used for the measurements of the films thicknesses. Ellipsometric data was modelled in the range of 1.3-5.0 eV using the TaucLorentz dispersion model. X-ray fluorescence (XRF) spectrometer Rigaku ZSX 400 and program ZSX Version 5.55 were used to measure the elemental composition of the films. Measurements were performed with a semi-quantitative (standardless analysis) program (SQX). SQX is a program to obtain concentrations of elements by theoretical calculation using the fundamental parameter (FP) method and internal sensitivity library.

The X-ray photoelectron spectra (XPS) were collected at normal emission using a Gammadata/Scienta SES100 hemispherical analyser and a Thermo VG Scientific XR3E2 non-monochromatic dual anode X-ray source $\left(\mathrm{Al}-\mathrm{K}_{\alpha} / \mathrm{Mg}-\mathrm{K}_{\alpha}\right)$. The analyser energy scale 
calibration was checked against the $4 \mathrm{f}_{7 / 2}$ line from cleaned gold foil at $84.0 \mathrm{eV}$ binding energy. Relevant to estimating elemental composition from XPS survey scans, the constant (i.e., independent of photoelectron kinetic energy) analyser transmission function was checked against accessible core level lines of clean $\mathrm{Au}, \mathrm{Ag}$ and $\mathrm{Cu}$ samples, and additionally asserted by constant magnification in spatial imaging (in the non-energy-dispersive direction) of a structured test sample through the electron optics over the entire used kinetic energy range). Spectral components were fitted, and elemental content from survey spectra was estimated using CasaXPS software [42]. XPS was exploited, in the first place, to detect the presence of carbon, complementarily to XRF, and study the differences of the carbon bonding in the films grown at two different temperatures, 250 and $300{ }^{\circ} \mathrm{C}$, i.e. that providing the most uniform films in terms of thickness, and that probably enabling higher degree of structural ordering, respectively. No preclean or surface etching was conducted before XPS measurements, since deposition of metal electrodes was in order after the deposition of oxide films, and that could not be carried out in a continuous process without exposure to the laboratory air. Nevertheless, since the probing and analysis depth of XPS extends through topmost 4-5 $\mathrm{nm}$ of a film, the method allowed one to acquire data adequately, sufficient for the description of bonding between elements constituting the solid layers. Different roles for carbon impurities were expected due to the lower rate of surface exchange reactions at lower temperatures. The crystal structure was evaluated by grazing incidence X-ray diffractometry (GIXRD), using an X-ray diffractometer SmartLab Rigaku with $\mathrm{CuK} \alpha$ radiation, which corresponds to an X-ray wavelength of $0.15406 \mathrm{~nm}$.

Resistive switching measurements were carried out by means of a semiconductor analyzer Keithley 4200SCS, with samples put in a light-tight probe station. The DC voltage was applied to the top electrode, leaving the bottom one grounded. The current-voltage curves were measured by applying voltage sweeps while incremental voltage pulses were applied in order to obtain the memory maps seen in Fig. 12. The resistive switching measurements appropriate for recording common current-voltage hystereses as well as those enabling admittance memory mapping have been described in a number of earlier studies, e.g., those devoted to $\mathrm{HfO}_{2}$ [43] and $\mathrm{ZrO}_{2}-\mathrm{Al}_{2} \mathrm{O}_{3}$ [44] based media. The aforementioned semiconductor analyzer can also be used to perform the Double Swing Quiescent Current (DSQC) technique [45], a novel method which would allow one to detect the polarization curves of thin film samples implying ferroelectric behaviour. 
Magnetic measurements were performed using Vibrating Sample Magnetometer (VSM) option of the Physical Property Measurement System 14T Quantum Design by scanning the magnetic field from -0.5 to $0.5 \mathrm{~T}$ parallel to the film surface at $300 \mathrm{~K}$ and -3.5 to $3.5 \mathrm{~T}$ at $5 \mathrm{~K}$.

\section{Results and discussion}

\section{Film growth and composition}

Data regarding the composition of films is given in Table I. Since the zirconium precursor contains chloride and the manganese precursor contains carbon, amounts of these elements were measured as well.

Table I. Thicknesses and manganese contents for studied samples with given process descriptions. Deposition temperature was $300^{\circ} \mathrm{C}$.

\begin{tabular}{|c|c|c|c|c|}
\hline Process description & Thickness, nm & $\mathrm{Mn} /(\mathrm{Mn}+\mathrm{Zr})$ & $\mathrm{Cl}$, at. $\%$ & C, at. \% \\
\hline $200 \mathrm{x}\left(\mathrm{ZrCl}_{4}+\mathrm{O}_{3}\right)$ & 26 & 0 & 0.7 & - \\
\hline $200 \times\left(\mathrm{Mn}(\mathrm{acac})_{3}+\mathrm{O}_{3}\right)$ & 50 & 1 & - & 33 \\
\hline $\begin{array}{l}100 \times\left(\mathrm{Mn}(\mathrm{acac})_{3}+\mathrm{O}_{3}\right)+100 \times \\
\left(\mathrm{ZrCl}_{4}+\mathrm{O}_{3}\right)\end{array}$ & $20+16(\mathrm{Mr}$ & 0.6 & 0.6 & 11 \\
\hline $\begin{array}{l}50 \times\left(\mathrm{Mn}(\mathrm{acac})_{3}+\mathrm{O}_{3}\right)+50 \mathrm{x} \\
\left(\mathrm{ZrCl}_{4}+\mathrm{O} 3\right)\end{array}$ & & 0.6 & 0.4 & 28 \\
\hline $\begin{array}{l}50 \mathrm{x}\left(\mathrm{Mn}(\mathrm{acac})_{3}+\mathrm{O}_{3}\right)+50 \mathrm{x} \\
\left(\mathrm{ZrCl}_{4}+\mathrm{O}_{3}\right)+50 \mathrm{x} \\
\left(\mathrm{Mn}(\mathrm{acac})_{3}+\mathrm{O}_{3}\right)+50 \mathrm{x} \\
\left(\mathrm{ZrCl}_{4}+\mathrm{O}_{3}\right)+50 \\
\left(\mathrm{Mn}(\mathrm{acac})_{3}+\mathrm{O}_{3}\right)\end{array}$ & $\begin{array}{l}7+7+7+7+7 \quad\left(\mathrm{MnO}_{\mathrm{x}}+\right. \\
\mathrm{ZrO}_{2}+\mathrm{MnO}_{\mathrm{x}}+\mathrm{ZrO}_{2}+ \\
\left.\mathrm{MnO}_{\mathrm{x}}\right)\end{array}$ & 0.7 & 1.3 & 11 \\
\hline
\end{tabular}

Certain issues became related to the uniformity of the film thickness along the gas flow direction in the flow-type reactor used in the experiments. For $\mathrm{ZrCl}_{4}$ as the $\mathrm{Zr}$ precursor in ALD, it is known, that this particular precursor does not decompose thermally even at elevated temperatures. Even at the substrate temperature of $500{ }^{\circ} \mathrm{C}$, the thickness of $\mathrm{ZrO}_{2}$ films grown from $\mathrm{ZrCl}_{4}$ and $\mathrm{H}_{2} \mathrm{O}$ may not deviate more than $12-15 \%$, measured along the substrate length [46]. Formation of certain thickness profile in chloride based ALD processes is probably inevitable in such flow-type reactors, possibly caused by the effect of secondary surface reactions, i.e., „poisoning“ of the surface by reaction products, that is $\mathrm{HCl}$ [47]. However, in the case of organic and oxygen-containing ligands to metals in the precursors 
like acetylacetonates, the thermal decomposition of the precursor can start in the gas phase during its transport in the reactor towards substrates, and, in this case at already slightly above $300{ }^{\circ} \mathrm{C}$, the oxide layer may, thus, deposit with higher rate, and preferentially, to the regions closer to the leading edge of the substrate. This has, evidently, became a considerable issue in the case of the manganese oxide process, as can be seen in the Figure 1.

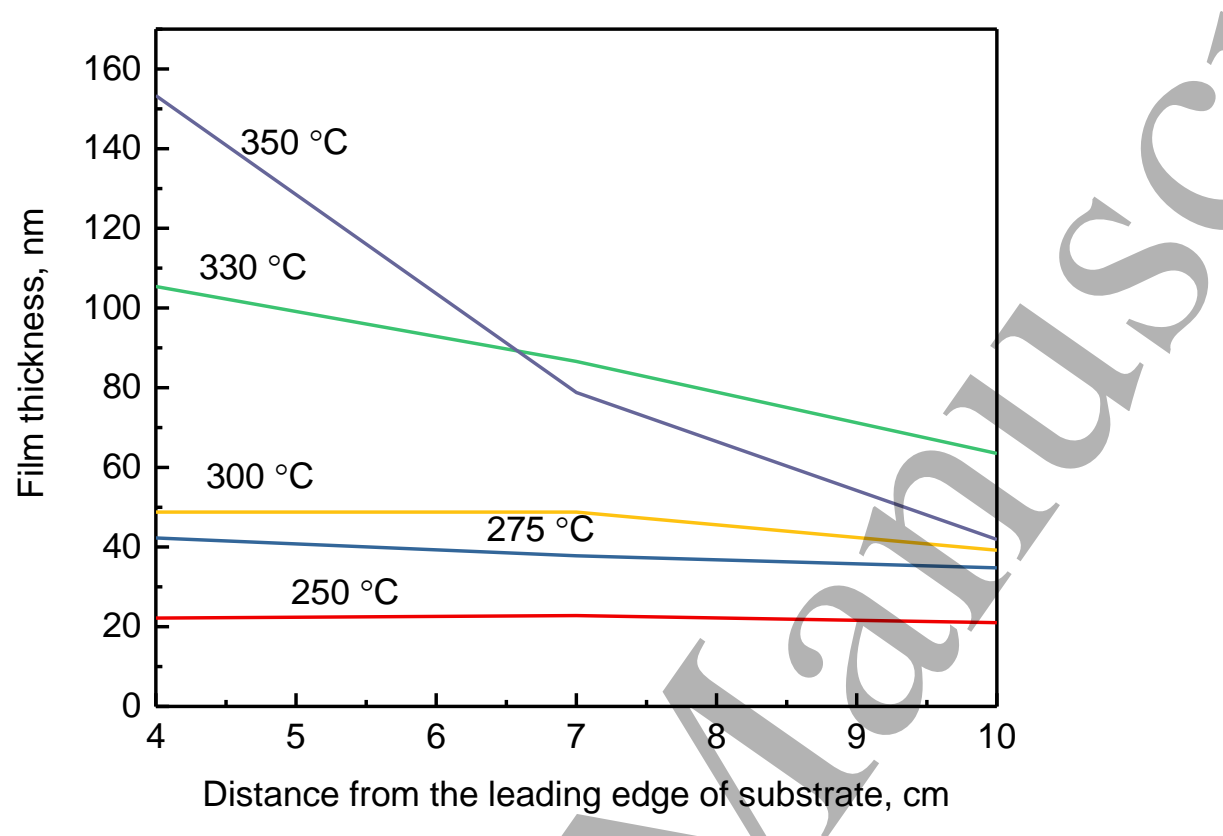

Figure 1. Manganese oxide film thicknesses úsing 200 ALD cycles at various deposition temperatures.

The XPS studies on elemental composition of the surface region of the films deposited at two different deposition temperatures 300 and $250{ }^{\circ} \mathrm{C}$ from XPS survey spectra revealed O:Mn content ratio approximately 1.4 for the film grown at $300{ }^{\circ} \mathrm{C}$, similarly to the value obtained by XRF. For the film grown at $250^{\circ} \mathrm{C}$, this content ratio increased up to 2.5 and, considering the probability of formation of surface carbonate instead of oxide, increasing with decreasing substrate temperature due to incomplete reactions, the results obtained from the film grown at $250{ }^{\circ} \mathrm{C}$ could be interpreted via 3-4 nm thick surface layers dominantly consisting of $\mathrm{MnCO}_{3}$

(Fig. 2). 


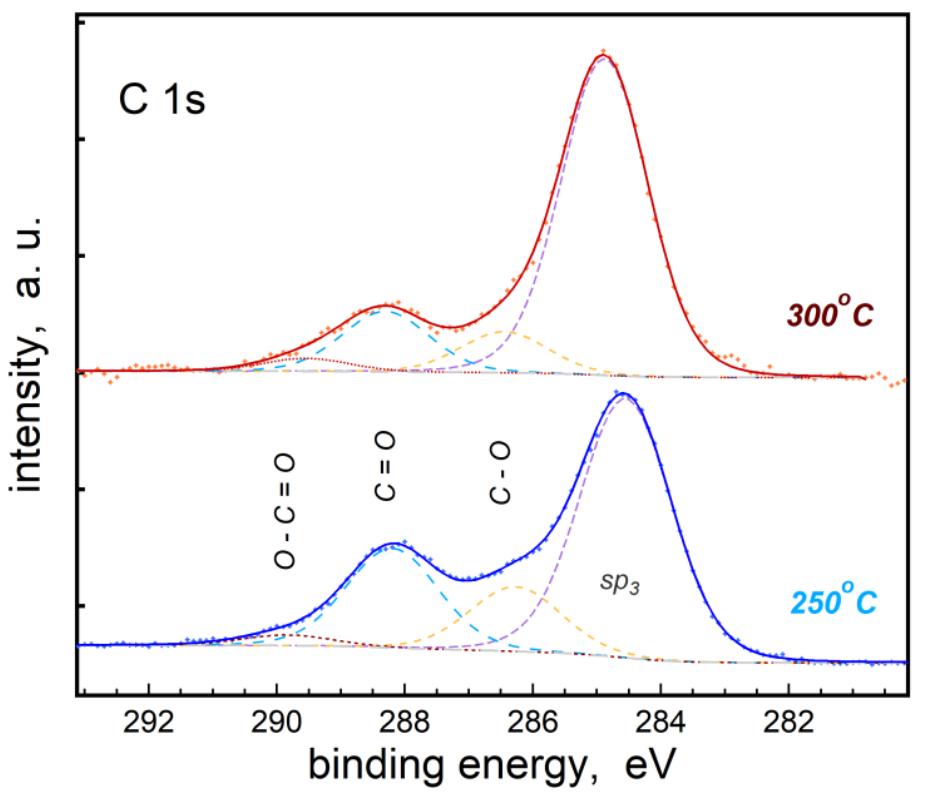

Figure 2. XPS results indicating the difference in contributions of residual carbon to the composition of manganese oxide films deposited at 250 and $300^{\circ} \mathrm{C}$.

The Mn 2p spectrum (Fig. 3), although at least partially demonstrating formation of solid manganese oxide in the present study, is generally not convenient to use for the identification of the Mn charge state due to the underlying ( $2 \mathrm{p}^{1}-3 \mathrm{~d}$ final state) multiplet and nontrivial spectral structure, but the main peak maxima positions suggest $2^{+}$and/or $3^{+} \mathrm{Mn}$ charge states, and the satellite peak (Fig. 3) at binding energies $\sim 5 \mathrm{eV}$ higher than the main lines (in the 250 ${ }^{\circ} \mathrm{C}$ deposited sample spectrum) can be regarded as that typical of $\mathrm{Mn}^{2+}$ [48]. The films grown at $250{ }^{\circ} \mathrm{C}$ remained highly disordered. Multiphase structure started to form and become detected by X-ray diffraction studies or films deposited at $300{ }^{\circ} \mathrm{C}$. The main diffraction maxima were attributed to tetragonal $\mathrm{Mn}_{3} \mathrm{O}_{4}$, while $\mathrm{Mn}_{2} \mathrm{O}_{3}$ was identified as an additional phase (Fig. 6), as will be described below. Both GIXRD and Mn 2p XPS implied that the phase composition of the MnOx films grown in the present study, especially at lowered temperatures, are complicated to define unambiguously (some further insight is provided from Mn 3s XPS, below). Besides, although manganese can take on all charge states from +7 to -3 , the most abundant (and stable) oxides have charge states $+2,+3$ and +4 , and the formula $\mathrm{Mn}_{3} \mathrm{O}_{4}$ can sometimes be written as $\mathrm{MnO} \cdot \mathrm{Mn}_{2} \mathrm{O}_{3}$, although such physical mixture picture would imply exchange interactions such that the magnetic properties would be that of an antiferromagnet (even at low temperatures), different from what we observe (below). 


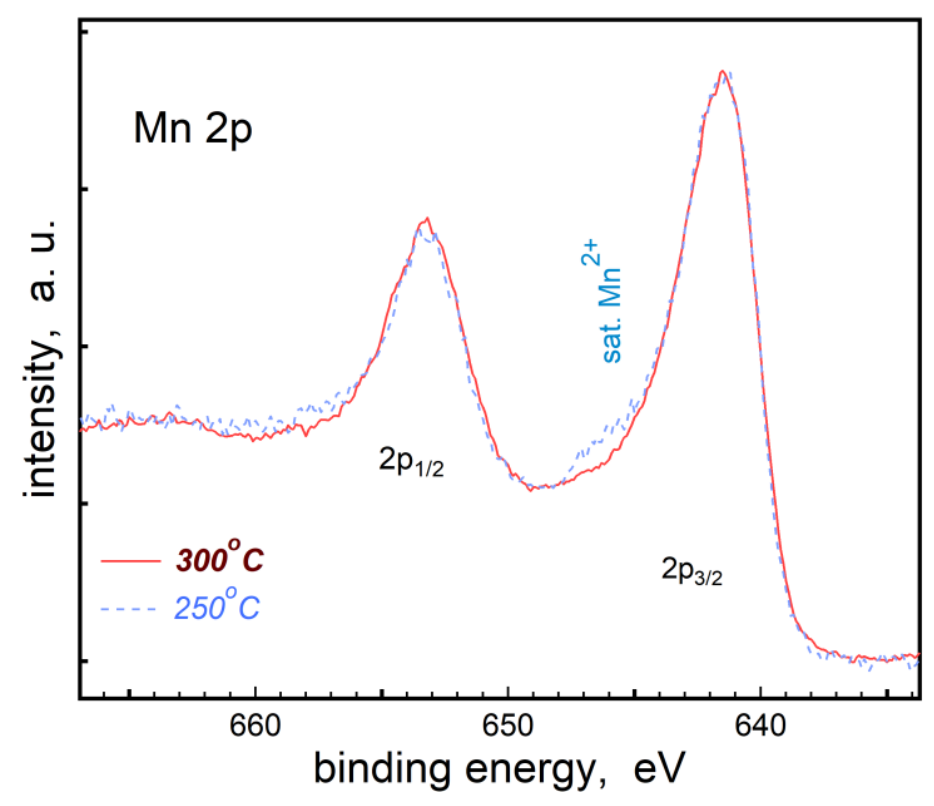

Figure 3. XPS results decribing the bonding of manganese cations in manganese oxide films deposited at 250 and $300{ }^{\circ} \mathrm{C}$.

Figure 4 depicts oxygen $1 \mathrm{~s}$ spectra obtained from the same reference films grown at temperatures of 250 and $300{ }^{\circ} \mathrm{C}$. The XPS spectrum for $\mathrm{O} 1 \mathrm{~s}$ acquired from the film grown at $300{ }^{\circ} \mathrm{C}$ demonstrated a dominant sharp peak at $529.9 \mathrm{eV}$, which is a value typical of bulk manganese oxides [49-51]. In addition, a shoulder structure was resolved and centred around $531.5 \mathrm{eV}$, which has been related to the presence of (surface) hydroxyl groups [52], accompanied by a smaller amount of C-O bonded impurity with the component peak above $532 \mathrm{eV}$ and a trace peak above $533 \mathrm{eV}$. The latter could be associated to physisorbed water vapour. However, the signals detected in the spectral region in the range of 531-534 eV would also accommodate and reveal double-bonded carbon of carbonates [53-54] and/or ketonate ligands [55], likely arising from the residues of the metal precursor also exploited in the present study, amply present in the film grown at $250^{\circ} \mathrm{C}$. 


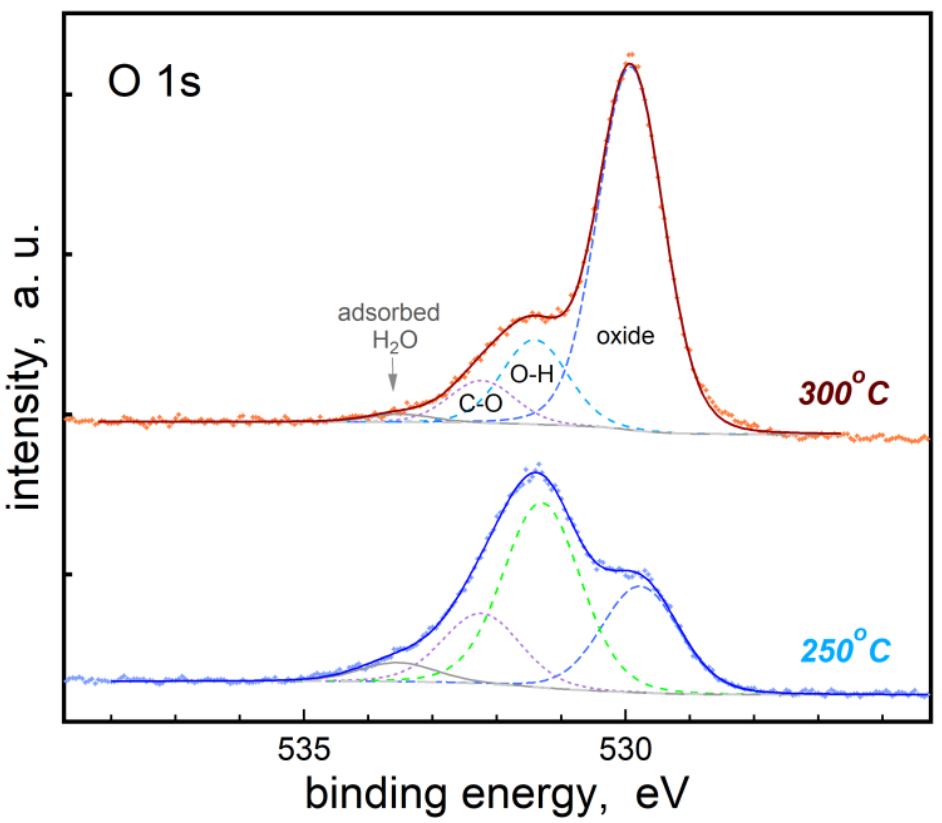

Figure 4. XPS spectra from manganese oxide films deposited at 250 and $300{ }^{\circ} \mathrm{C}$.

The multiplet (exchange) splitting in the Mn 3s [56] due to the remaining single 3 s electron in the final state having spin either parallel or antiparallel to the aligned spins of the $3 \mathrm{~d}$ valence electrons has allowed to distinguish less ambiguously between the different Mn charge states. The size of this splitting depends also on the type of bonding (hybridisation) and typically stays at less than half of the theoretically estimated value of $\sim 13 \mathrm{eV}$ [57]. It is experimentally observed to range from $4.3 \mathrm{eV}$ for $\mathrm{Mn}^{4+}$ to $\sim 6 \mathrm{eV}$ for $\mathrm{Mn}^{2+}[50,58]$. The $\mathrm{Mn} 3 \mathrm{~s}$ splitting measured in the present study (Fig. 5) exhibited a peak separation of $5.9 \mathrm{eV}$ for the film deposited at $300{ }^{\circ} \mathrm{C}$. The spectral shape occurred virtually identical to that of bulk $\mathrm{Mn}_{3} \mathrm{O}_{4}$ measured earlier [58]. In the present study, the observation is also supported by the GIXRD results, allowing one to consider the $\mathrm{Mn}_{3} \mathrm{O}_{4}$ as dominant crystalline phase in such films. One can note that separation of the peaks in the measured photoelectron spectrum appears to differ significantly from those in the dominantly $\mathrm{Mn}^{3+}$ containing model compounds [58-59]. At the same time, the spectrum measured from the film grown at $250{ }^{\circ} \mathrm{C}$ possessed quite a similar shape (Fig. 5), but the peak separation is perceptibly, even if by as little as $0.1 \mathrm{eV}$, larger, and the lower binding energy component at $83 \mathrm{eV}$ narrower, which is consistent with the features characteristic of a material containing significant amounts of $\mathrm{MnCO}_{3}$, as deduced from estimates from $\mathrm{C} 1 \mathrm{~s}$ and $\mathrm{O}$ 1s XPS above. 


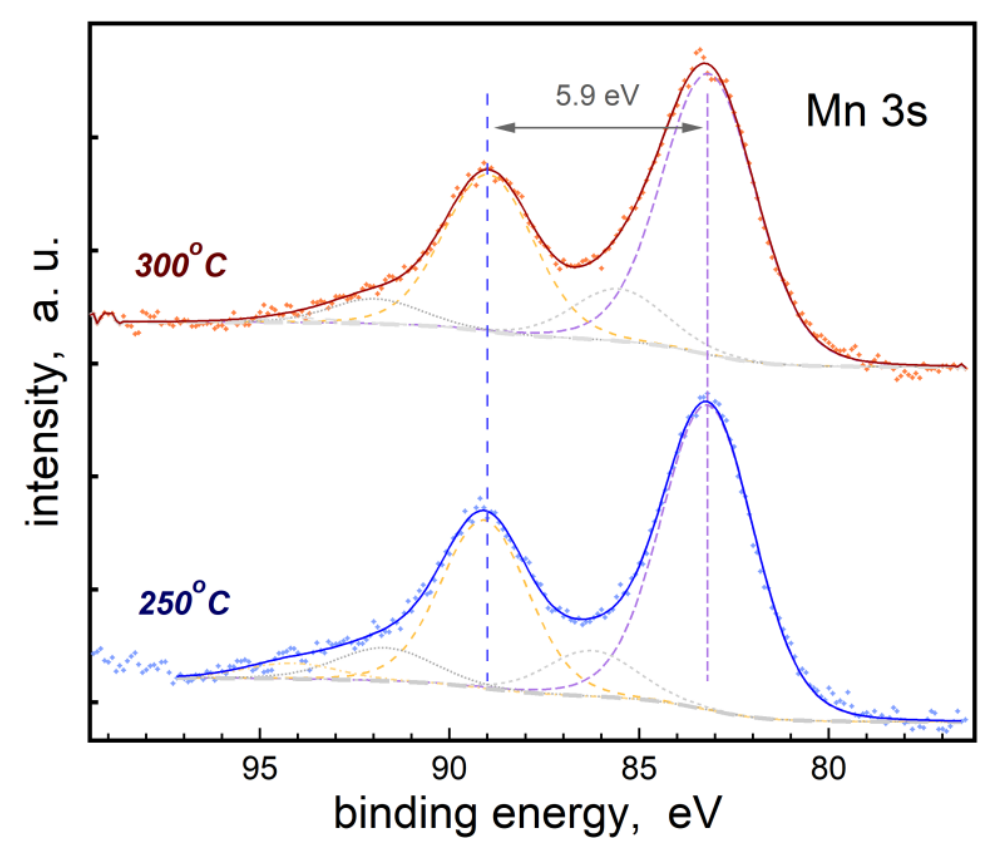

Figure 5. X-ray photoelectron spectra for Mn 3s lines measured from manganese oxide films grown at 250 and $300{ }^{\circ} \mathrm{C}$.

In further experiments aiming at tailoring oxides of manganese and zirconium, the $\mathrm{MnOx}$ growth process was carried out at $300{ }^{\circ} \mathrm{C}$, providing films with acceptable thickness uniformity and with much less carbon residues. In reference growth experiments, 200, 100, and 50 ALD cycles of manganese oxide at $300{ }^{\circ} \mathrm{C}$ resulted in films thicknesses of 50, 20, and $7 \mathrm{~nm}$, respectively. This implies that the growth of the film was not linear against the amount of the deposition cycles, but increased from 0.14 to $0.25 \mathrm{~nm} /$ cycle. Most likely this is caused by the inhibited nucleation in the early stage of the film growth, whilst after certain film thickness e.g. number of cycles, the linear growth begins. The initial nucleation determines the structure formation and hence the film properties, which in turn is dependent on the type of substrate and its surface functionalization, precursor chemistry and deposition temperature used in ALD process. The composition measurements allowed one to state that the value of $x$ for $\mathrm{MnO}_{\mathrm{x}}$ was around 1.4, irrespectively of the thickness.

\section{Film structure}

As mentioned above, in $\mathrm{MnO}_{\mathrm{x}}$ films $\mathrm{x}=1.4$, measured by $\mathrm{XRF}$, implying the formation of a mixture of crystalline compounds with different stoichiometry. The GIXRD studies of films deposited at $300{ }^{\circ} \mathrm{C}$ revealed, that both the cubic phase of $\mathrm{Mn}_{2} \mathrm{O}_{3}$ (PDF Card 01-078-0390) and tetragonal phase of $\mathrm{Mn}_{3} \mathrm{O}_{4}$ (PDF Card 00-018-0803) were present in the manganese oxide films not combined with $\mathrm{ZrO}_{2}$ (Fig. 6). Moreover, one diffraction maximum attributable to 
tetragonal $\mathrm{MnO}_{2}$ (PDF Card 01-072-1982) could be recognized, although the appearance of a solitary reflection is not enough to confidently claim the corresponding phase actually formed in the films. $\mathrm{ZrO}_{2}$ was found to be formed as a mixture of cubic (PDF Card 01-077-3168) and tetragonal (PDF Card 01-075-9649) phases. These phases can be difficult to distinguish, since several diffraction maxima tend to overlap. However, the 211 reflection of the tetragonal $\mathrm{ZrO}_{2}$ polymorph was unambiguously recognized (Fig. 6), neighbouring the closely located 311 reflection of the cubic $\mathrm{ZrO}_{2}$. The intensities of diffraction maxima are somewhat correlated to the thickness of films, whereby multi-layered structures demonstrating less intense maxima than those observed in non-laminated reference films, since their thicknesses are lower as well.

For a comparison with literature data, Mattelaer et al. [21] have demonstrated the possibility to control phase composition of ALD-grown manganese oxides by applying either $\mathrm{Mn}(\mathrm{thd})_{3}$ and $\mathrm{O}_{3}$, or $\mathrm{Mn}(\mathrm{thd})_{3}$ and $\mathrm{NH}_{3}$ plasma as precursors, followed by annealing the as-deposited $\mathrm{MnO}$ or $\mathrm{MnO}_{2}$ films either in reducing or oxidative ambient in the temperature range of 450$900{ }^{\circ} \mathrm{C}$. Nilsen et al. [36] have grown $\mathrm{MnO}_{2}$ films by ALD also from $\mathrm{Mn}(\text { thd })_{3}$ and $\mathrm{O}_{3}$ at 186 ${ }^{\circ} \mathrm{C}$ in a flow type ALD reactor. In the latter study, additional test experiments revealed that $\mathrm{Mn}_{3} \mathrm{O}_{4}$ could be grown at $200{ }^{\circ} \mathrm{C}$ using $\mathrm{O}_{3}$ under atmospheric pressure, otherwise the $\mathrm{Mn}_{3} \mathrm{O}_{4}$ was achieved after increasing the substrate temperature above $230{ }^{\circ} \mathrm{C}$. In addition, Ghods et al. [37] have obtained $\mathrm{MnO}$ thin films by ALD at substrate temperature of $200{ }^{\circ} \mathrm{C}$ using $\mathrm{Mn}(\mathrm{acac})_{3}$ and $\mathrm{H}_{2} \mathrm{O}$ as precursors. In the latter study, the stoichiometry of $\mathrm{MnO}$ was determined by X-ray photoelectron spectroscopy. 


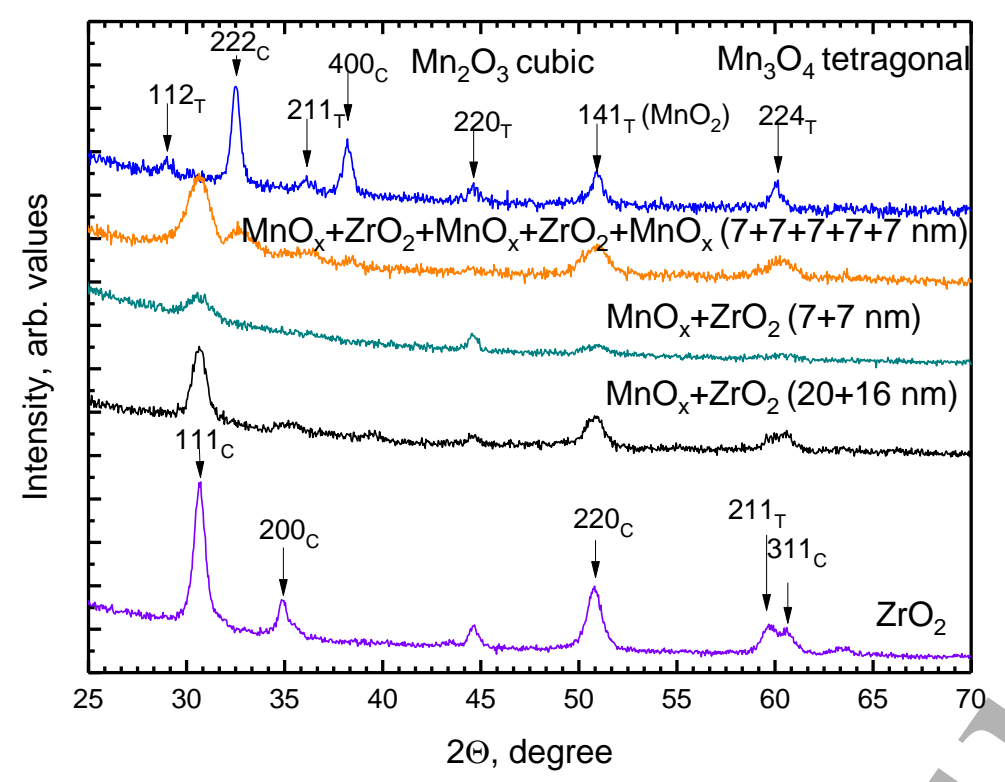

Figure 6. GIXRD diffractograms of selected multi-layered structures as well as reference zirconia and manganese oxide films, denoted by the labels. Miller indices of diffraction maxima are given for all distinct maxima, whereby $\mathrm{T}$ and $\mathrm{C}$ denote the tetragonal and cubic phase, respectively. Thicknesses of $\mathrm{ZrO}_{2}$ and manganese oxide reference films were 26 and $50 \mathrm{~nm}$, respectively

\section{Electrical and magnetic properties}

The films demonstrated nonlinear saturative magnetization with hystereses and moderate but measurable coercive fields similar to those common for ferromagnetic materials. Notably, Figure 7 shows room temperature ferromagnetic-like behaviour, most markedly apparent in the thinnest nanolaminate, with a saturation value of $1.5 \cdot 10^{-6} \mathrm{emu}$. Similar magnetic moment values in $\mathrm{ZrO}_{2}$ films and its laminated structures with other metal oxides have been obtained by various authors $[39,60-61]$. 


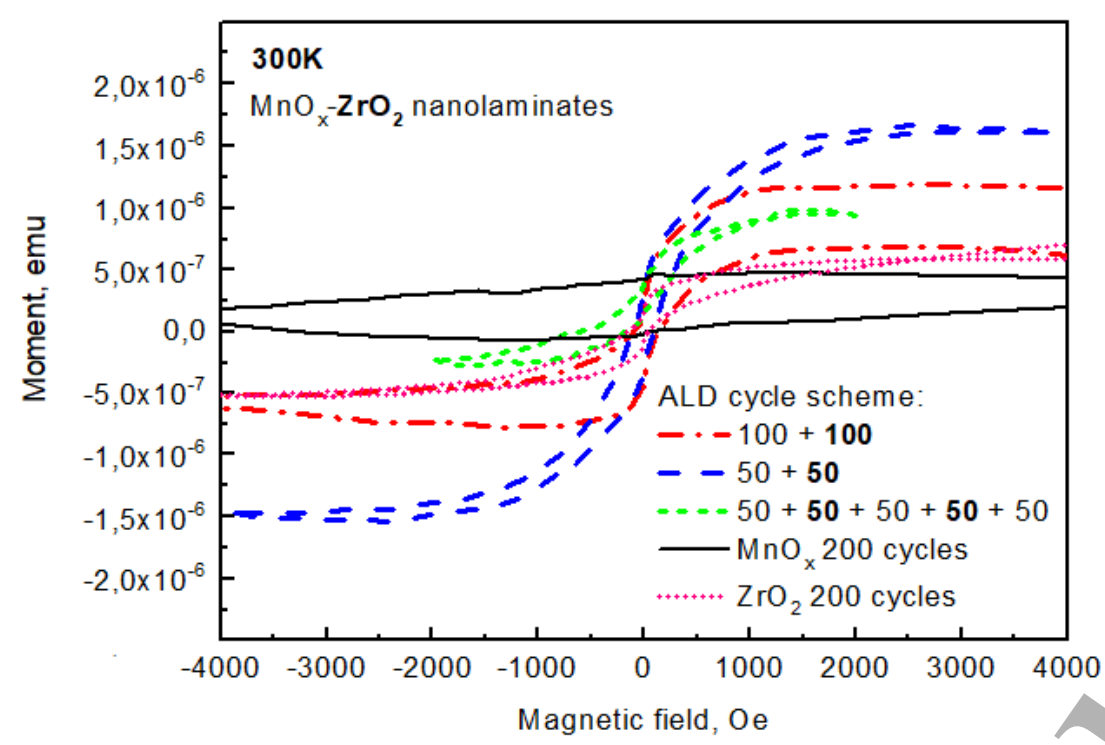

Figure 7. Magnetic moment versus external magnetic field graphs of the samples at $300 \mathrm{~K}$. The amounts of $\mathrm{ZrO}_{2}$ deposition cycles are given in bold.

There are several manganese oxides known to have magnetic ordering at lower temperatures. Worth mentioning are antiferromagnetic $\mathrm{Mn}_{2} \mathrm{O}_{3}, \mathrm{Mn}_{5} \mathrm{O}_{8}$ and $\mathrm{MnO}$ with Neel ordering temperatures of $75 \mathrm{~K}, 131 \mathrm{~K}$ and $115 \mathrm{~K}$ respectively, and ferrimagnetic $\mathrm{Mn}_{3} \mathrm{O}_{4}$ with Curie point around $46 \mathrm{~K}$ [62-64].

The most prominent feature from our temperature dependent zero field cooled (ZFC) and field cooled (FC) magnetization measurements is the bifurcation (irreversibility) of ZFC-FC loops and a large increase in magnetization below $46 \mathrm{~K}$ (Fig. 10), which coincides with the Curie temperature of $\mathrm{Mn}_{3} \mathrm{O}_{4}$ and clearly indicates the presence of the ferrimagnetic oxide in all four of the samples. No cusp or maxima in ZFC-FC curves indicating any of the antiferromagnetic (AFM) transitions could be detected. If the AFM phases exist in the samples, then their magnetic moment is below the sensitivity level of the PPMS VSM used in the measurements. Temperature dependent susceptibility of the pure $\mathrm{ZrO}_{2}$ was flat and featureless, appropriate for a diamagnetic material.

Low temperature magnetic isotherm or hysteresis loops measured at $5 \mathrm{~K}$ only confirmed the existence of $\mathrm{Mn}_{3} \mathrm{O}_{4}$ in all of the samples. The coercive field $\left(\mathrm{H}_{\mathrm{c}}\right)$ measured was $10.1 \mathrm{kOe}$ for the non-laminated $\mathrm{MnO}_{\mathrm{x}}$ film as well as for most laminates (Fig. 8 and 9). It was slightly higher for the $50+50+50+50+50$ film at about $11.5 \mathrm{kOe}$ (Fig. 9). Such high values of $\mathrm{H}_{\mathrm{c}}$ have previously been reported for $\mathrm{Mn}_{3} \mathrm{O}_{4}$ nanoparticles with small crystallite sizes. [65] Figure 9 is 
the same as Figure 8, but with the manganese oxide film excluded, since the saturation magnetization value for manganese oxide is so high that other samples are barely distinguishable on the graph in Figure 8.

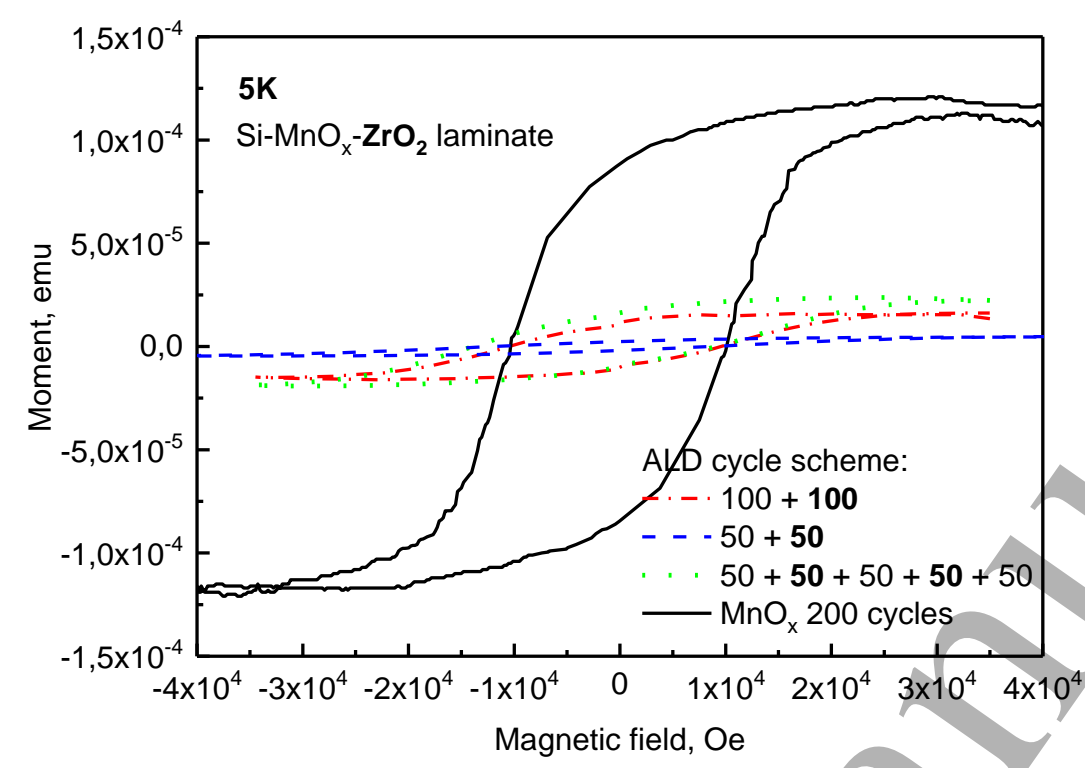

Figure 8. Magnetic moment against external magnetic field curves of all the $\mathrm{MnO}_{\mathrm{x}}$ and $\mathrm{ZrO}_{2-}$ $\mathrm{MnO}_{\mathrm{x}}$ films measured at $5 \mathrm{~K}$.

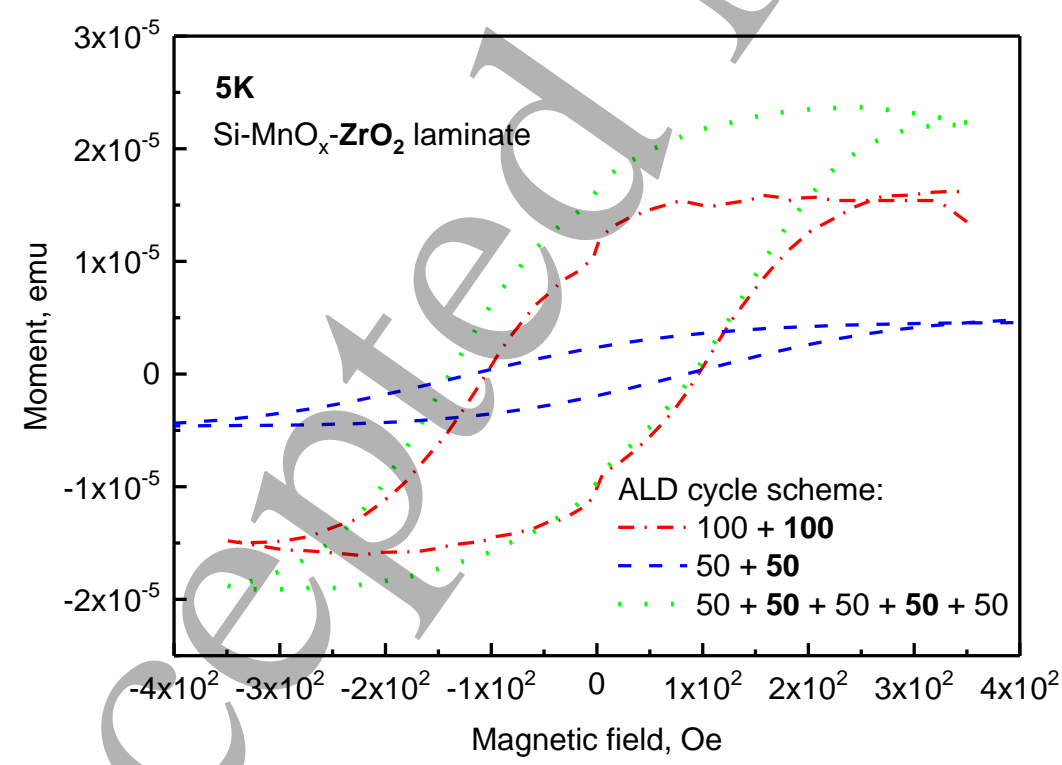

Figure 9. Magnetic moment against external magnetic field curves of the $\mathrm{ZrO}_{2}-\mathrm{MnO}_{\mathrm{x}}$ samples at $5 \mathrm{~K}$. Manganese oxide film has been excluded from this image. 


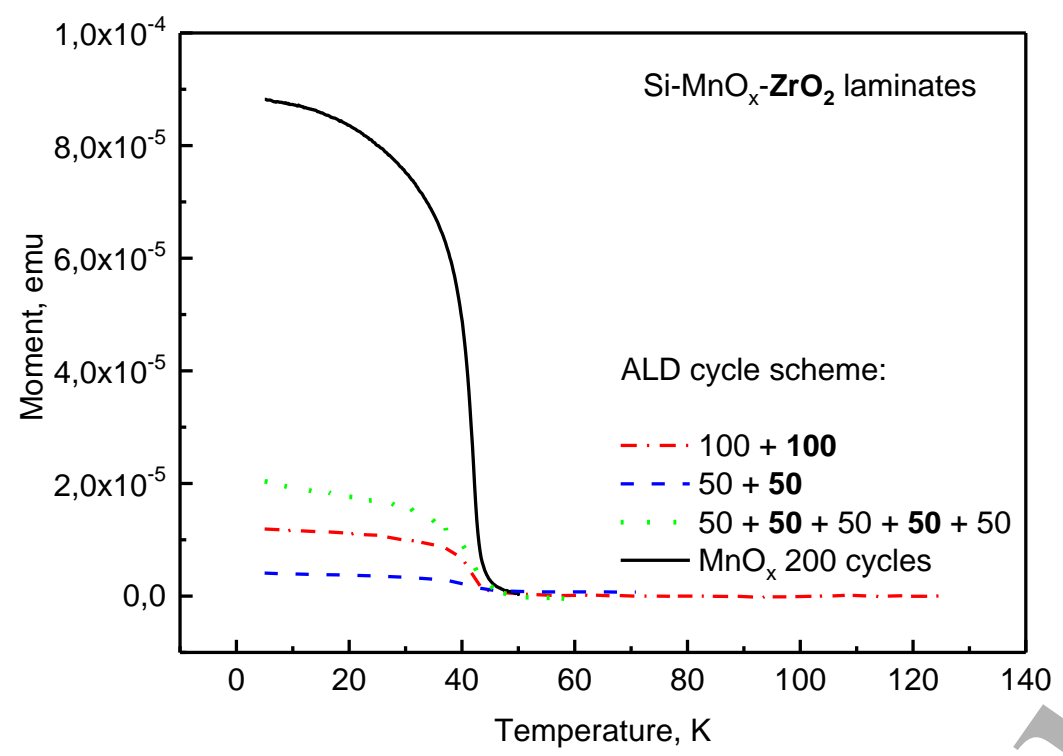

Figure 10. Magnetic moment - temperature dependence for $\mathrm{MnO}_{\mathrm{x}}-\mathrm{ZrO}_{2}$ and $\mathrm{MnO}_{\mathrm{x}}$ films.

All films exhibited resistive switching (RS) characteristics (Fig. 11). This means that, under electrical stimulus, these samples change their resistance state and retain its value even when the power is turned off (non-volatile effect). It has earlier been established that the physics associated with RS involves the movement of both ions and electrons [66]. Furthermore, these devices require an electroforming step [67], an initial electrical stress necessary to activate the switching property. After this process, the characteristic RS current-voltage (I-V) curves can be obtained. Bivalued curves which present two distinctive conduction states referred to as the high-resistance (HRS) and the low-resistance (LRS).

The pure (non-laminated) $\mathrm{MnO}_{\mathrm{x}}$ and $\mathrm{ZrO}_{2}$ samples presented the widest functional windows (Fig. 11-a and 11-b), along with the $50 \times \mathrm{MnO}_{\mathrm{x}}+50 \times \mathrm{ZrO}_{2}(50+50$ sample/film), which was the thinnest film as grown. The window narrowed as the number of cycles increased, as we can see when comparing the $50+50$ and the $100 \times \mathrm{MnO}_{\mathrm{x}}+100 \times \mathrm{ZrO}_{2}$ samples $(100+100$ sample/film) (Fig. 11-c). This is also shown in Figure 12, in which the memory maps [68] drawn from the same films are depicted. This fact can be explained taking into account that the number of ALD cycles determines the thickness of the film (14 nm versus $36 \mathrm{~nm}$, in this case). The 100+100 film also demonstrated the narrowest window together with the multilayer film, which consisted of five sequential layers in stack. In addition to the thickness values ( $36 \mathrm{~nm}$ and $35 \mathrm{~nm}$ respectively), this might be due to the existence of several interfaces between the constituent layers, which could hinder the formation of the conductive filament. 

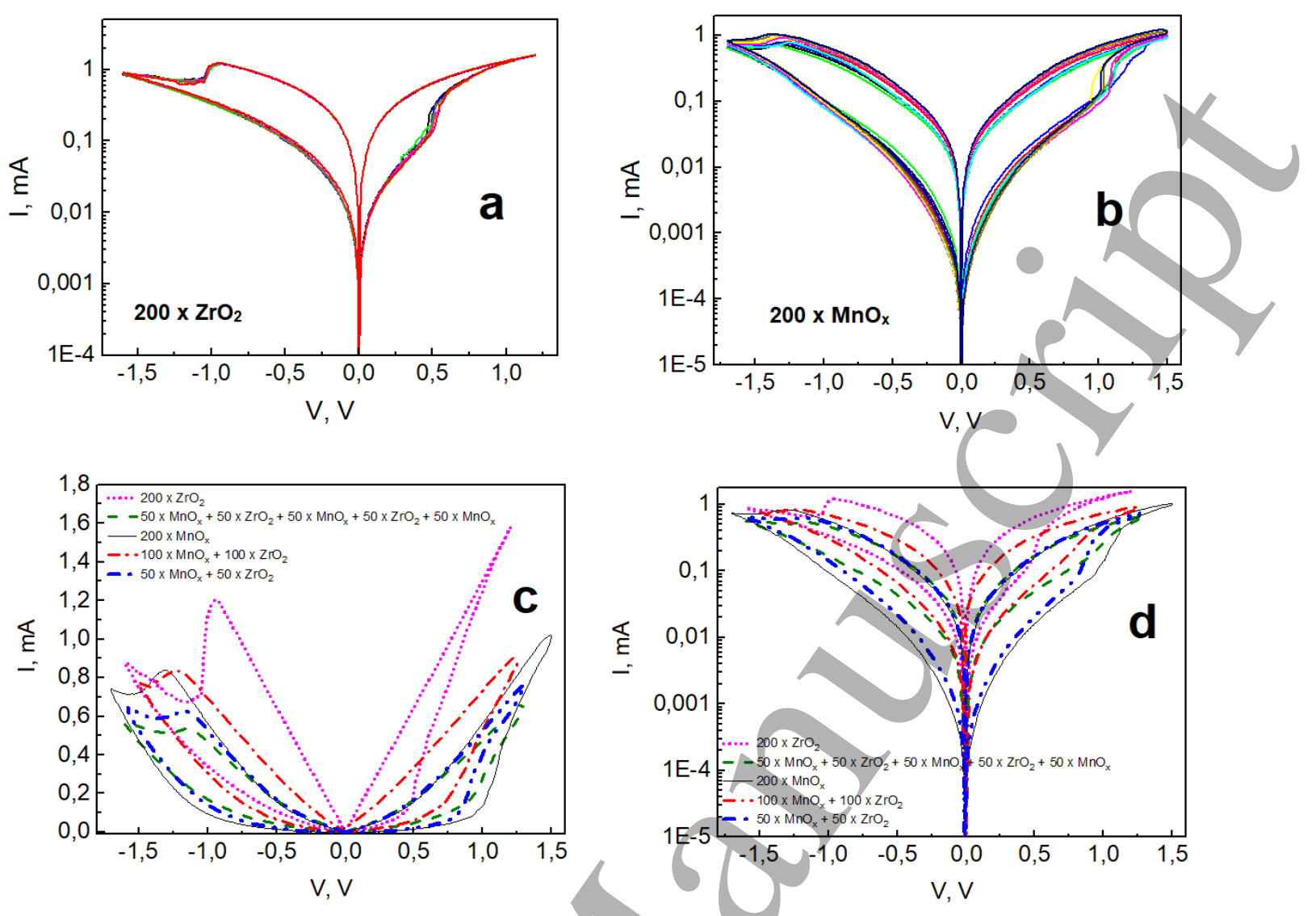

Figure 11. Current - Voltage cycles of pure $\mathrm{ZrO}_{2}(\mathrm{a})$, and $\mathrm{MnO}_{\mathrm{x}}(\mathrm{b})$ samples, and average current-voltage loops of all the films on a linear scale (c) and on a logarithmic scale (d).

The non-laminated $\mathrm{ZrO}_{2}$ film had the lowest SET and RESET voltages (Fig. 11-a). However, this film was also the one with the highest current values for both LRS and HRS states (see also Fig. 12-a), showing, at the same time, the steepest SET and RESET transitions. At first glance, this could be seen as an advantage, as these transitions are also the fastest of all the samples. Nevertheless, this steep transition implies that $\mathrm{ZrO}_{2}$ samples alone may not perform well in multilevel applications, and the high current values may simply make it the least suitable for non-volatile-memory applications, as the power consumption would remain high. The results for non-laminated $\mathrm{ZrO}_{2}$ results are in a good accordance with the ones presented earlier by Ossorio et al. [69]. 

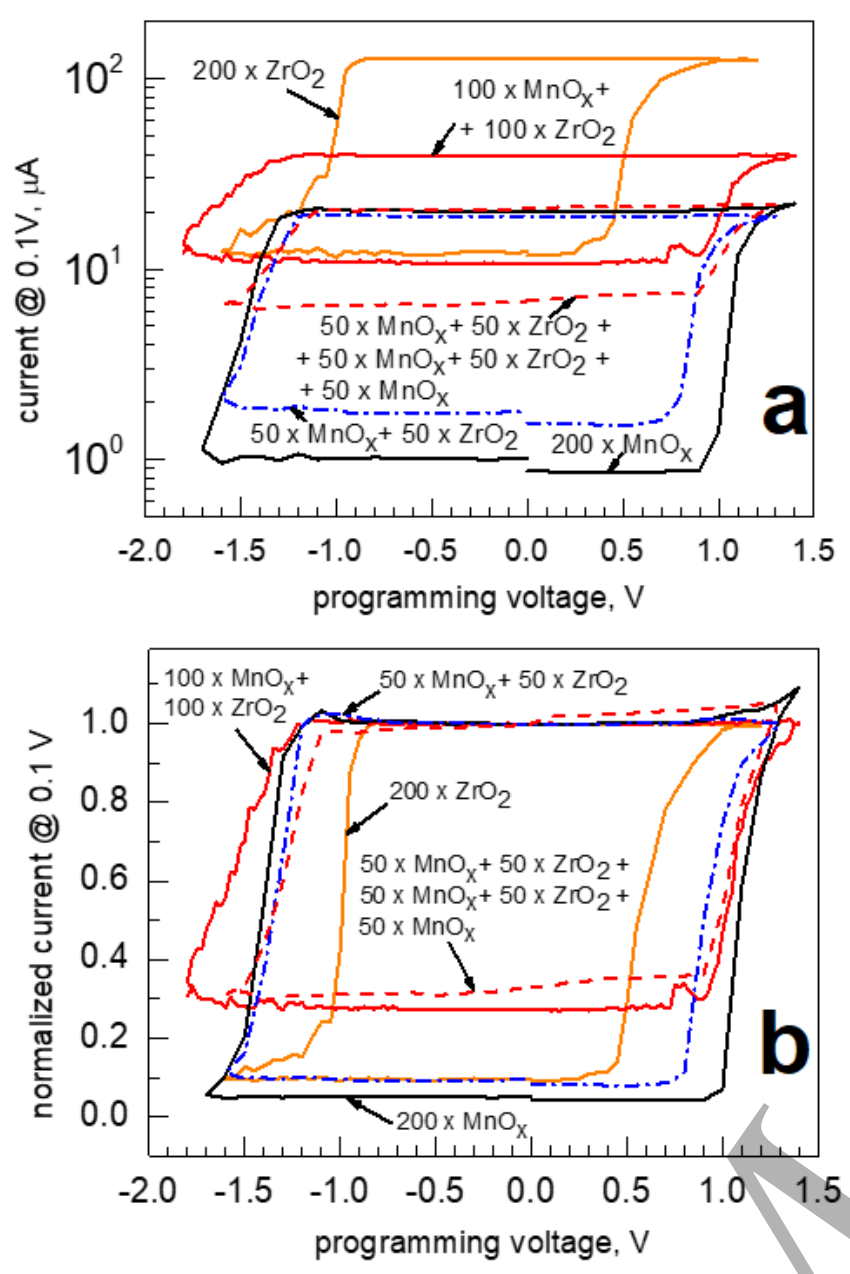

Figure 12. Memory maps (a) and normalized memory maps (b) of the different samples. These maps are obtained by/reading the current at $0.1 \mathrm{~V}$ after applying a previous programming voltage. The normalized values are obtained by considering the LRS as a value of 1.0 .

The non-laminated $\mathrm{MnO}_{\mathrm{x}}$ sample the lowest current values for both high and low resistance states (Figs. 11-b, 11-c), which provide similar resistance values to those determined by Zhang et al. [70] when applying Ohm's law to the current values obtained for both HRS and LRS in the memory map that can be seen in Figure 12. The memory maps are an image of the state of the RRAM cell after a previous stress stimulus, and are obtained by measuring some representative magnitude of the state at voltages low enough so that the measurement process itself does not alter the state of the device $[68,71]$.

The low current values, along with a notably wide functional window (Fig. 12-b), make the $\mathrm{MnO}_{\mathrm{x}}$ film the most adequate for memory applications. Additionally, this sample presented smooth SET and RESET transitions, thus showing multilevel capabilities, which have been 
demonstrated to be useful for neuromorphic applications, i.e., artificial neural networks, as they might behave as electronic synapses [72].

The latter is also true for the $\mathrm{MnO}_{\mathrm{x}}-\mathrm{ZrO}_{2}$ mixed samples, which all presented smooth SET and RESET transitions, as well as lower HRS and LRS currents when comparing them to the nonlaminated $\mathrm{ZrO}_{2}$ film. Thus, $\mathrm{MnO}_{\mathrm{x}}-\mathrm{ZrO}_{2}$ films might become further investigated and suited to multilevel applications, as implied especially by the $100+100$ sample film, which demonstrated the smoothest transitions. On the other hand, these stacks possessed rather narrow functional windows and, consequently, may not regarded as the most appropriate for memory applications, with the exception of the 50+50 sample, which really exhibited high ratio between HRS and LRS as well as appreciably low current values.

\section{Summary}

$\mathrm{ZrO}_{2}$ and manganese oxide films, as well as their layered structures, were deposited by ALD, using $\mathrm{ZrCl}_{4}, \mathrm{Mn}(\mathrm{acac})_{3}$ and ozone. XPS results confirmed significant contribution from carbon containing species in the manganese oxide film deposited at $250{ }^{\circ} \mathrm{C}$, allowing one to consider even the formation and presence of $\mathrm{MnCO}_{3}$. At the same time, in the film deposited at $300{ }^{\circ} \mathrm{C}$, essentially weaker role for residual carbon, and formation of $\mathrm{Mn}_{3} \mathrm{O}_{4}$ was detected and determined by both XPS and GIXRD. Therefore, $300{ }^{\circ} \mathrm{C}$ was chosen for the deposition temperature for nanolaminates. Non-laminated $\mathrm{ZrO}_{2}$ was found to form in its cubic and tetragonal polymorphs, whereas non-laminated manganese oxide possessed cubic $\mathrm{Mn}_{2} \mathrm{O}_{3}$ and tetragonal $\mathrm{Mn}_{3} \mathrm{O}_{4}$ phases. All the films were found to behave as ferromagnetic-like materials. At the same time, hysteretic charge polarization - electric field behaviour was not registered, and also the Double Swing Quiescent Current method measurements did not imply any ferroelectric behaviour. Manganese oxide films demonstrated both saturation magnetization and coercivity values by two orders of magnitude higher at $5 \mathrm{~K}$, compared to the values measured at $300 \mathrm{~K}$. In $\mathrm{ZrO}_{2}-\mathrm{MnO}_{\mathrm{x}}$ films and nanolaminates, the polarization values at the aforementioned temperatures reached differed by about ten times. Manganese oxide lost its high magnetization value at $40-45 \mathrm{~K}$.

All films exhibited excellent resistive switching characteristics with almost no difference between their commutation values. However, there appeared remarkable differences in the current values linked to both high and low resistance states, with the non-laminated $\mathrm{ZrO}_{2}$ sample film showing the highest ratios between these states. The non-laminated $\mathrm{MnO}_{\mathrm{x}}$ film 
possessed the lowest ratio, while in the different $\mathrm{ZrO}_{2}-\mathrm{MnO}_{\mathrm{x}}$ samples the ratio between high and low resistance states varied. Both non-laminated samples present great functional windows between each resistance state. Nevertheless, the mixed $\mathrm{ZrO}_{2}-\mathrm{MnO}_{\mathrm{x}}$ films have very different windows between these states, with the $50 \times \mathrm{MnO}_{\mathrm{x}}+50 \times \mathrm{ZrO}_{2}$ showing a great functional window, while the $100 \times \mathrm{MnO}_{\mathrm{x}}+100 \times \mathrm{ZrO}_{2}$ and the multilayer film show the narrowest windows. This is explained by the variation in thickness and the fact that the multiple interfaces between the layer could hinder the formation of the filament. These results prove the potential interest of the $\mathrm{MnO}_{\mathrm{x}}$ and $\mathrm{ZrO}_{2} / \mathrm{MnO}_{\mathrm{x}}$-based MIM structures in both nonvolatile memories and neuromorphic applications.

\section{Acknowledgements}

The present study was partially funded by the European Regional Development Fund projects "Emerging orders in quantum and nanomaterials" (TK134), "Adyanced materials and hightechnology devices for sustainable energetics, sensorics and nanoelectronics" (TK141), Spanish Ministry of Economy and Competitiveness (TEC2017-84321-C4-2-R) with support of Feder funds and Estonian Research Agency (PRG4, PRG753).

\section{References}

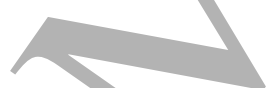

1. Gottmann J and Kreutz E W 1999 Pulsed laser deposition of alumina and zirconia thin films on polymers and glass as optical and protective coatings Surface and Coatings Technology 116-119 1189-1194, https://doi.org/10.1016/S0257-8972(99)00191-7

2. Edlou S M, Smajkiewicz A, Al-Jumaily G A 1993 Optical properties and environmental stability of oxide coatings deposited by reactive sputtering Appl. Opt. 32 5601-5605. https://doi.org/10.1364/A0.32.005601

3. Sorek Y, Zevin M, Reisfeld R, Hurvits T and Ruschin S 1997 Zirconia and Zirconia-ORMOSIL Planar Waveguides Prepared at Room Temperature Chem. Mater. 9 670-676. https://doi.org/10.1021/cm960135x

4. Jasieniak J, Pacifico J, Signorini R, Chiasera A, Ferrari M, Martucci A and Mulvaney P 2007 Luminescence and Amplified Stimulated Emission in CdSe-ZnS-Nanocrystal-Doped 
$\mathrm{TiO}_{2}$ and $\mathrm{ZrO}_{2}$ Waveguides Advanced Functional Materials 17 1654-1662. https://doi.org/10.1002/adfm.200600955

5. Okamoto H, Obayashi H and Kudo T 1980 Carbon monoxide gas sensor made of stabilized zirconia Solid State Ionics 1319-326. https://doi.org/10.1016/0167-2738(80)90012-0

6. Miura N, Nakatou M and Zhuiykov S 2003 Impedancemetric gas sensor based on zirconia solid electrolyte and oxide sensing electrode for detecting total $\mathrm{NO}_{\mathrm{x}}$ at high temperature Sensors and Actuators B: Chemical 93 221-228. https://doi.org/10.1016/S09254005(03)00196-5

7. Houssa M, Afanasiev V V, Stesmans A and Heyns M M 2000 Variation in the fixed charge density of $\mathrm{SiO}_{\mathrm{x}} / \mathrm{ZrO}_{2}$ gate dielectric stacks during postdeposition oxidation Appl. Phys. Lett. 77 1885-1887. https://doi.org/10.1063/1.1310635

8. Lin C Y, Wang S Y, Lee D Y and Tseng T Y 2008 Electrical properties and fatigue behaviors of $\mathrm{ZrO}_{2}$ resistive switching thin films Journal of The Electrochemical Society 155 H615-H619. https://doi.org/10.1149/1.2946430

9. Müller J, Böscke T S, Schröder U, Mueller S, Bräuhaus D, Böttger U, Frey L and Mikolajick T 2012 Ferroelectricity in Simple Binary $\mathrm{ZrO}_{2}$ and $\mathrm{HfO}_{2}$ Nano Letters 12 43184323. https://doi.org/10.1021/nl302049k

10. Weeks S L, Pal A, Narasimhan V K, Littáu K A and Chiang T 2017 Engineering of Ferroelectric $\mathrm{HfO}_{2}-\mathrm{ZrO}_{2}$ Nanolaminates ACS Appl. Mater. Interfaces 9 13440-13447. https://doi.org/10.1021/acsami.7b00776

11. Jia X, Yang W, Qin M and Li J 2009 Structure and magnetism in Mn-doped zirconia: Density-functional theory studies Journal of Magnetism and Magnetic Materials $3212354-$ 2358. https://doi.org/10.1016/j.j.jmmm.2009.02.132

12. Dimri M C, Kooskora H, Pahapill J, Joon E, Heinmaa I, Subbi J and Stern R 2011 Search for ferromagnetism in manganese-stabilized zirconia Physica Status Solidi A - Applications and Materials Science 208 172-179. https://doi.org/10.1002/pssa.201026304

13. Hong N H, Kanoun M B, Goumri-Said S, Song J H, Chikoidze E, Dumont Y, Ruyter A and Kurisu M 2013 The origin of magnetism in transition metal-doped $\mathrm{ZrO}_{2}$ thin films: experiment and theory Journal of Physics: Condensed Matter 25436003. https://døi.org/10.1088/0953-8984/25/43/436003 
14. Dimri M C, Khanduri H, Kooskora H, Kodu M, Jaaniso R, Heinmaa I, Mere A, Krustok J and Stern R 2012 Room-temperature ferromagnetism in Ca and Mg stabilized cubic zirconia Journal of Physics D - Applied Physics 45 475003. https://doi.org/10.1088/0022$\underline{3727 / 45 / 47 / 475003}$

15. Chouhan L, Bouzerar G and Srivastava S K 2020 d(0) Ferromagnetism in Ag-doped $\begin{array}{llllll}\text { monoclinic } & \mathrm{ZrO}_{2} & \text { compounds } & \text { Vacuum } & 182 & 109716 .\end{array}$ https://doi.org/10.1016/j.vacuum.2020.109716

16. Ning S, Zhan P, Xie Q, Li Z and Zhang Z 2013 Room-temperature ferromagnetism in undoped $\mathrm{ZrO} 2$ thin films Journal of Physics D: Applied Physics $\mathbf{4 6} 445004$. https://doi.org/10.1088/0022-3727/46/44/445004

17. Pattanaik S, Mishra D K, Sharma M K and Chatterjee R 2020 Experimental evidences of ferromagnetism in undoped monoclinic zirconia Inorganic Chemistry Communications 118 108042. https://doi.org/1016/j.inoche.2020.108042

18. Oyama S T 2000 Chemical and catalytic properties of ozone Catalysis Reviews 42 279322. https://doi.org/10.1081/CR-100100263

19. Torresi S C and Gorenstrein A 1992 Electrochromic behaviour of manganese dioxide electrodes in slightly alkaline solutions Electrochimica acta 37 2015-2019. https://doi.org/10.1016/0013-4686(92)87117-I

20. Strandwitz N C, Comstock D J, Grimm R L, Nichols-Nielander A C, Elam J and Lewis N S 2013 Photoelectrochemical behavior of n-type Si (100) electrodes coated with thin films of manganese oxide grown by atomic layer deposition The Journal of Physical Chemistry C 117 4931-4936. https://doi,org/10.1021/jp311207x

21. Mattelaer F, Bosserez T, Rongé J, Martens J A, Dendooven J and Detavernier C 2016 Manganese oxide films with controlled oxidation state for water splitting devices through a combination of atomic layer deposition and post-deposition annealing RSC advances 698337 98343. https://doi.org/10.1039/C6RA19188F

22. Gao P, Meng L J, Dos Santos M P, Teixeira V and Andritschky M 2000 Characterisation of $\mathrm{ZrO}_{2}$ films prepared by rf reactive sputtering at different $\mathrm{O}_{2}$ concentrations in the sputtering gases Vacuum 56 143-148. https://doi.org/10.1016/S0040-6090(00)01395-X 
23. Landorf R W and Licht S J 1972 Sputtered Manganese Dioxide as Counterelectrodes in Thin Film Capacitors Journal of The Electrochemical Society 119430. https://doi.org/10.1149/1.2404223

24. Neubeck W, Ranno L, Hunt M B, Vettier C and Givord D 1999 Epitaxial MnO thin films grown by pulsed laser deposition Applied surface science $\mathbf{1 3 8}$ 195-198. https://doi.org/10.1016/S0169-4332(98)00421-8

25. Shen Y, Shao S, Yu H, Fan Z, He H and Shao J 2007 Influences of oxygen partial pressure on structure and related properties of $\mathrm{ZrO}_{2}$ thin films prepared by electron beam evaporation deposition Applied surface science $254 \quad 552-556$. https://doi.org/10.1016/j.apsusc.2007.06.029

26. Seike T and Nagai J 1991 Electrochromism of 3d transition metal oxides Solar energy materials 22 107-117. https://doi.org/10.1016/0165-1633(91)90010-I

27. Jeon T S, White J M, Kwong D L 2001 Thermal stability of ultrathin $\mathrm{ZrO}_{2}$ films prepared by chemical vapor deposition on Si (100) Applied Physics Letters 78 368-370. https://doi.org/10.1063/1.1339994

28. Rizzi G A, Zanoni R, Di Siro S, Perriello L and Granozzi G 2000 Epitaxial growth of $\mathrm{MnO}$ nanoparticles on $\mathrm{Pt}(111)$ by reactive deposition of $\mathrm{Mn}_{2}(\mathrm{CO})_{10}$ Surface science 462187 194. https://doi.org/10.1016/S0039-6028(00)00608-7

29. Perednis D, Wilhelm O, Pratsinis S E and Gauckler L J 2005 Morphology and deposition of thin yttria-stabilized zirconia films using spray pyrolysis Thin solid films 474 84-95. https://doi.org/10.1016/j.tsf.2004.08.014

30. Valletta R M and Pliskin W A 1967 Preparation and characterization of manganese oxide thin films Journal of The Electrochemical Society 114 944. https://doi.org/10.1149/1.2426786

31. Kukli K, Niinistö J, Tamm A, Lu J, Ritala M, Leskelä M and Putkonen M 2007 Atomic layer deposition of $\mathrm{ZrO}_{2}$ and $\mathrm{HfO}_{2}$ on deep trenched and planar silicon Microelectronic engineering 84 2010-2013. https://doi.org/10.1016/j.mee.2007.04.035

32. Aarik L, Alles H, Aidla A, Kahro T, Kukli K, Niinistö J and Mändar H Influence of process parameters on atomic layer deposition of $\mathrm{ZrO}_{2}$ thin films from $\mathrm{CpZr}\left(\mathrm{NMe}_{2}\right)_{3}$ and $\mathrm{H}_{2} \mathrm{O}$ Thin Solid Films 565 37-44. https://doi.org/10.1016/j.tsf.2014.06.052 
33. Kim H, McIntyre P C and Saraswat K C 2004 Microstructural evolution of $\mathrm{ZrO}_{2}-\mathrm{HfO}_{2}$ nanolaminate structures grown by atomic layer deposition Journal of materials research 19 643-650. https://doi.org/10.1557/jmr.2004.19.2.643

34. Tamm A, Kozlova J, Aarik L, Aidla A, Lu J, Kiisler A A, Kasikov A, Ritslaid P, Mändar H, Hultman L, Sammelselg V, Kukli K and Aarik J 2014 Atomic layer deposition of $\mathrm{ZrO}_{2}$ for graphene-based multilayer structures: In situ and ex situ characterization of growth process physica status solidi (a) 211 397-402. https://doi.org/10.1002/pssa.201330106

35. Lin Y C, McGuire F and Franklin A D 2018 Realizing ferroelectric $\mathrm{Hf}_{0.5} \mathrm{Zr}_{0.5} \mathrm{O}_{2}$ with elemental capping layers Journal of Vacuum Science \& Technology B, Nanotechnology and Microelectronics: Materials, Processing, Measurement, and Phenomena 36011204. https://doi.org/10.1116/1.5002558

36. Nilsen $\mathrm{O}$, Fjellvåg $\mathrm{H}$ and Kjekshus A 2003 Growth of manganese oxide thin films by atomic layer deposition Thin Solid Films 444 44-51. https://doi.org/10.1016/S0040$\underline{6090(03) 01101-5}$

37. Ghods A, Zhou C and Ferguson I T 2020 Structural and optical properties of (Zn, Mn) O thin films prepared by atomic layer deposition Journal of Vacuum Science \& Technology A: Vacuum, Surfaces, and Films 38 042408. https://doi.org/10.1116/6.0000141

38. Arroval T, Aarik L, Rammula R, Kruusla V and Aarik J 2016 Effect of substrateenhanced and inhibited growth on atomic layer deposition and properties of aluminumtitanium oxide films Thin Solid Films 6000 119-125. $\underline{\text { http://dx.doi.org/10.1016/j.tsf.2016.01.024 }}$

39. Kalam K, Seemen H, Ritslaid P, Rähn M, Tamm A, Kukli K, Kasikov A, Link J, Stern R, Dueñas S and Castán H 2018 Atomic layer deposition and properties of $\mathrm{ZrO}_{2} / \mathrm{Fe}_{2} \mathrm{O}_{3}$ thin films Beilstein Journal of Nanotechnology 9 119-128. http://dx.doi.org/10.3762/bjnano.9.14

40. Granneman E, Fischer P, Pierreux D, Terhorst H and Zagwijn P 2007 Batch ALD: Characteristics, comparison with single wafer ALD, and examples Surface and coatings technology 201 8899-8907. https://doi.org/10.1016/j.surfcoat.2007.05.009

41. Zagwijn P M, Verweij W, Pierreux D, Adjeroud N, Bankras R, Oosterlaken E, Snijders G J, Van den Hout M, Fischer P, Wilhelm R and Knapp M 2008 Novel Batch Titanium Nitride CVD Process for Advanced Metal Electrodes ECS Transactions $\mathbf{1 3} 459$. https://doi.org/10.1149/1.2911530 
42. Fairley N 2018 CasaXPS: Processing Software for XPS, AES, SIMS and More (Casa Software Ltd., 2018) [online] http://www.casaxps.com/. [Google Scholar]

43. Castán H, Dueñas S, García H, Ossorio O G, Domínguez L A, Sahelices B, Miranda E, González M B and Campabadal F 2018 Analysis and control of the intermediate memory states of RRAM devices by means of admittance parameters Journal of Applied Physics 124 152101. https://doi.org/10.1063/1.5024836

44. Castán H, Dueñas S, Kukli K, Kemell M, Ritala M and Leskelä M 2018 Study of the influence of the dielectric composition of $\mathrm{Al} / \mathrm{Ti} / \mathrm{ZrO}_{2}: \mathrm{Al}_{2} \mathrm{O}_{3} / \mathrm{TiN} / \mathrm{Si} / \mathrm{Al}$ structures on the resistive switching behavior for memory applications ECS Transactions 85 143-148. https://doi.org/10.1149/08508.0143ecst

45. Dueñas S, Castán H, Ossorio O G, Vinuesa G, García H, Kukli K and Leskelä K 2020 Double Swing Quiescent-Current: An Experimental Detection Method of Ferroelectricity in Very Leaky Dielectric Films ECS Transactions 97 3-6. https://doi.org/10.1149/09701.0003ecst

46. Ritala M and Leskelä M 1994 Zirconium dioxide thin films deposited by ALE using zirconium tetrachloride as precursor Applied Surface Science $\mathbf{7 5}$ 333-340. https://doi.org/10.1016/0169-4332(94)90180-5

47. Siimon H and Aarik J 1997 Thickness profiles of thin films caused by secondary reactions in flow-type atomic layer deposition reactors Journal of Physics D: Applied Physics 301725. https://doi.org/10.1088/0022-3727/30/12/006

48. Bocquet A E, Mizokawa T, Morikawa K, Fujimori A, Barman S R, Maiti K, Sarma D D, Tokura Y and Onoda M 1996 Electronic structure of early 3d-transition-metal oxides by analysis of the $2 \mathrm{p}$ core-level photoemission spectra Phys. Rev. B $\mathbf{5 3} 1161$. https://doi.org/10.1103/PhysRevB.53.1161

49. NIST X-ray Photoelectron Spectroscopy Database, NIST Standard Reference Database Number 20, National Institute of Standards and Technology, Gaithersburg MD, 20899 (2000), https://doi.org/10.18434/T4T88K, (retrieved Nov. 22, 2020).

50. Stranick M A $1999 \mathrm{MnO}_{2}$ by XPS Surface Science Spectra 631. https://doi.org/10.1116/1.1247888 
51. Stranick M A $1999 \quad \mathrm{Mn}_{2} \mathrm{O}_{3}$ by XPS Surface Science Spectra 639. $\underline{\text { https://doi.org/10.1116/1.1247889 }}$

52. Yamamoto S, Bluhm H, Andersson K, Ketteler G, Ogasawara H, Salmeron M and Nilsson A 2008 In situ x-ray photoelectron spectroscopy studies of water on metals and oxides at ambient conditions J. Phys.: Condens. Matter 20 184025. https://doi.org/10.1088/0953$\underline{8984 / 20 / 18 / 184025}$

53. Shi S, Zhang M, Deng T, Wang T and Yang G 2017 A facile strategy to construct binderfree flexible carbonate composite anode at low temperature with high performances for lithium-ion batteries Electrochimica Acta https://doi.org/10.1016/j.electacta.2017.06.135

54. Zhang Y X and Jia Y 2018 Fluoride adsorption on manganese carbonate: Ion-exchange based on the surface carbonate-like groups and hydroxyl groups Journal of Colloid and Interface Science $\mathbf{5 1 0}$ 407-417. https://doi.org/10.1016/j.jcis.2017.09.090

55. Stranick M A $1999 \mathrm{Mn}\left(\mathrm{C}_{2} \mathrm{H}_{3} \mathrm{O}_{2}\right)_{2}$ by XPS Surface Science Spectra 647. $\underline{\text { https://doi.org/10.1116/1.1247893 }}$

56. Fadley C S, Shirley D A, Freeman A J, Bagus P S and Mallow J W 1969 Multiplet Splitting of Core-Electron Binding Energies in Transition-Metal Ions Phys. Rev. Lett. 23 1397. https://doi.org/10.1103/PhysRevLett.23.1397

57. Takahashi M and Igarashi J $2010 \mathrm{Ab}$ initio study of 3s core-level x-ray photoemission $\begin{array}{lllllll}\text { spectra in transition metals Phys. Rev. B } & \mathbf{8 1} & 035118 .\end{array}$ https://doi.org/10.1103/PhysRevB.81.035118

58. Galakhov V R, Demeter M, Bartkowski S, Neumann M, Ovechkina N A, Kurmaev E Z, Lobachevskaya N I, Mukovskii Y M, Mitchell J and Ederer D L 2002 Mn 3s exchange splitting in mixed-valence manganites Phys. Rev. B 65113102. https://doi.org/10.1103/PhysRevB.65.113102

59. Ilton E S, Post J E, Heaney P J, Ling F T and Kerisit S N 2016 XPS determination of Mn oxidation states in Mn (hydr)oxides Applied Surface Science 366 475-485. https://doi.org/10.1016/j.apsusc.2015.12.159

60. Kalam K, Seemen H, Mikkor M, Ritslaid P, Stern R, Duenas S, Castan H, Tamm A and Kukli K 2018 Electric and Magnetic Properties of Atomic Layer Deposited $\mathrm{ZrO}_{2}-\mathrm{HfO}_{2}$ Thin 
Films ECS Journal of Solid State Science and Technology 7 N117. https://doi.org/10.1149/2.0041809jss

61. Sangalli D, Cianci E, Lamperti A, Ciprian R, Albertini F, Casoli F, Lupo P, Nasi L, Campanini M and Debernardi A 2013 Exploiting magnetic properties of Fe doping in zirconia The European Physical Journal B 86 211. https://doi.org/10.1140/epjb/e2013-30669-3

62. Thota S, Prasad B, Kumar J 2010 Formation and magnetic behaviour of manganese oxide nanoparticles Materials Science and Engineering $B \quad 167 \quad 153-160$. https://doi:10.1016/j.mseb.2010.01.049

63. Liu C, Yun F and Morkoc H 2005 Ferromagnetism of $\mathrm{ZnO}$ and GaN: a review Journal of Materials Science: Materials in Electronics 16 555. https://doi.org/10,1007/s10854-005$\underline{3232-1}$

64. Moharreri E, Hines W A, Biswas S, Perry D M, He J, Murray-Simmons D and Suib S L 2018 Comprehensive magnetic study of nanostructured mesoporous manganese oxide materials and implications for catalytic behavior Chemistry of Materials 30 1164-1177. https://doi.org/10.1021/acs.chemmater.7b05280

65. Wang Z H, Geng D Y, Hu W J, Ren W J, Zhang Z D 2009 Magnetic properties and exchange bias in $\mathrm{Mn}_{2} \mathrm{O}_{3} / \mathrm{Mn}_{3} \mathrm{O}_{4}$ nanoclusters Journal of Applied Physics 105 07A315. https://doi.org/10.1063/1.3055349

66. Waser R, Dittmann R, Staikov G and Szot K 2009 Redox-Based Resistive Switching Memories - Nanoionic Mechanisms, Prospects, and Challenges Advanced Materials 213754. https://doi.org/10.1002/adma.200900375

67. Yang J J, Miao F, Pickett M D, Ohlberg D A A, Stewart D R, Lau C N and Williams R S 2009 The mechanism of electroforming of metal oxide memristive switches Nanotechnology 20 215201. https://doi.org/10.1088/0957-4484/20/21/215201

68. Dueñas S, Castán H, Kukli K, Mikkor M, Kalam K, Arroval T and Tamm A 2018 Memory Maps: Reading RRAM Devices without Power Consumption ECS Transactions 85 201. https://doi.org/10.1149/08508.0201ecst

69. Ossorio O G, Dueñas S, Castán H, Tamm A, Kalam K, Seemen H and Kukli K 2019 Resistive Switching Properties of Atomic Layer Deposited $\mathrm{ZrO}_{2}-\mathrm{HfO}_{2}$ Thin Films Spanish Conference on Electron Devices (CDE) 1-4. https://doi.org/10.1109/CDE.2018.8596925 
70. Zhang S, Long S, Guan W, Liu Q, Wang Q and Liu M 2009 Resistive switching characteristics of $\mathrm{MnO}_{\mathrm{x}}$-based ReRAM Journal of Physics D: Applied Physics 42055112. https://doi.org/10.1088/0022-3727/42/5/055112

71. Castán H, Dueñas S, García H, Ossorio O G, Domínguez L A, Sahelices B, Miranda E, González M B and Campabadal F 2018 Analysis and control of the intermediate memory states of RRAM devices by means of admittance parameters Journal of Applied Physics 124 152101. https://doi.org/10.1063/1.5024836

72. Maestro-Izquierdo M, Gonzalez M B and Campadabal F 2019 Mimicking the spiketiming dependent plasticity in $\mathrm{HfO}_{2}$-based memristors at multiple time scales Microelectronic Engineering 215 111014. https://doi.org/10.1016/j.mee.2019.111014 